\title{
Regulation of ATP binding cassette transporter A1 (ABCA1) expression: cholesterol-dependent and - independent signaling pathways with relevance to inflammatory lung disease
}

\author{
Patrick He ${ }^{1,2}$, Ingrid C. Gelissen ${ }^{3}$ and Alaina J. Ammit ${ }^{1,2^{*}}$ (i)
}

\begin{abstract}
The role of the ATP binding cassette transporter A1 (ABCA1) in maintaining cellular lipid homeostasis in cardiovascular disease is well established. More recently, the important beneficial role played by ABCA1 in modulating pathogenic disease mechanisms, such as inflammation, in a broad range of chronic conditions has been realised. These studies position ABCA1 as a potential therapeutic target in a diverse range of diseases where inflammation is an underlying cause. Chronic respiratory conditions such as asthma and chronic obstructive pulmonary disease (COPD) are driven by inflammation, and as such, there is now a growing recognition that we need a greater understanding of the signaling pathways responsible for regulation of ABCA1 expression in this clinical context. While the signaling pathways responsible for cholesterol-mediated ABCA1 expression have been clearly delineated through decades of studies in the atherosclerosis field, and thus far appear to be translatable to the respiratory field, less is known about the cholesterol-independent signaling pathways that can modulate ABCA1 expression in inflammatory lung disease. This review will identify the various signaling pathways and ligands that are associated with the regulation of ABCA1 expression and may be exploited in future as therapeutic targets in the setting of chronic inflammatory lung diseases.
\end{abstract}

Keywords: ABCA1, COPD, Inflammation, TNF, Cholesterol, Cigarette smoke

\section{Background}

ATP binding cassette transporter A1 (ABCA1) is a transmembrane transporter protein ubiquitously expressed in human tissue, and found in abundance in the liver and lungs (reviewed in [1]). While its primary role is to maintain lipid homeostasis by controlling the efflux of cellular

\footnotetext{
* Correspondence: Alaina.Ammit@uts.edu.au

'Woolcock Emphysema Centre, Woolcock Institute of Medical Research, University of Sydney, Sydney, NSW, Australia

${ }^{2}$ School of Life Sciences, Faculty of Science, University of Technology Sydney, Sydney, NSW, Australia

Full list of author information is available at the end of the article
}

cholesterol and phospholipids, ABCA1 is increasingly recognised as having anti-inflammatory functions in a diverse range of diseases where inflammation is an underlying pathogenic mechanism (reviewed in [1-4]). Thus, given the role played by $\mathrm{ABCA} 1$ in suppressing inflammation, understanding the signaling pathways that regulate ABCA1 expression may provide potential therapeutic strategies to maintain cholesterol homeostasis and treat conditions with excessive inflammation in the future.

(C) The Author(s). 2020 Open Access This article is licensed under a Creative Commons Attribution 4.0 International License, which permits use, sharing, adaptation, distribution and reproduction in any medium or format, as long as you give appropriate credit to the original author(s) and the source, provide a link to the Creative Commons licence, and indicate if changes were made. The images or other third party material in this article are included in the article's Creative Commons licence, unless indicated otherwise in a credit line to the material. If material is not included in the article's Creative Commons licence and your intended use is not permitted by statutory regulation or exceeds the permitted use, you will need to obtain permission directly from the copyright holder. To view a copy of this licence, visit http://creativecommons.org/licenses/by/4.0/ The Creative Commons Public Domain Dedication waiver (http://creativecommons.org/publicdomain/zero/1.0/) applies to the data made available in this article, unless otherwise stated in a credit line to the data. 


\section{ABCA1-mediated cholesterol efflux}

ABCA1 transporter plays an important role in maintaining cellular cholesterol homeostasis by participating in the reverse cholesterol transport pathway (RCT) [5]. ABCA1 expressed in peripheral cells facilitates the export of cellular cholesterol to its extracellular acceptor protein apolipoprotein-A1 (apoA-1) [6]. In macrophages, ABCA1 interacts with apoA-1 to develop nascent high density lipoprotein (HDL) before interacting with ATP binding cassette transporter G1 (ABCG1) and scavenger receptor class B type 1 to from mature HDL particles [7]. Subsequently, HDL transports the cholesterol from peripheral tissues to the liver for excretion [6].

\section{Altered ABCA1 expression in lung diseases}

Mutations in ABCA1 can cause Tangier disease, a rare genetic disorder characterized by a substantial reduction in HDL levels [8]. Studies investigating the roles of ABCA1 in RCT have since observed similarities in the phenotype of ABCA1 deficient mice compared to the phenotype of human Tangier disease $[9,10]$. The phenotype of ABCA1-knockout mice macrophages in vivo included lipid accumulation and significantly reduced HDL and apoA-1 levels [9]. Lipid accumulation as a result of reduced HDL and apoA-1 in ABCA1 and ABCG1 knockout mice macrophages was found to induce increased circulating pro-inflammatory cytokines, displaying signs of systemic inflammation $[9,10]$. In addition, while similar outcomes were found in vitro with the knockdown of ABCA1 in human macrophages, ABCG1 expression was increased [11].

Evidence from both in vitro and in vivo studies have shown ABCA1 expression is altered in lung diseases such as COPD [12, 13]. In a recent study, Sonett et al. found that the expression of $\mathrm{ABC}$ transporters (ABCA1 and $A B C G 1)$ in lungs of patients with moderate to severe $C O P D$ to be significantly downregulated compared to healthy lungs [12]. In addition, greater downregulation of ABCA1 expression was observed compared to ABCG1 indicating that the importance of ameliorating downregulated ABCA1 may outweigh downregulated ABCG1 [12]. Cigarette smoke is proposed as the primary cause of downregulated ABCA1 expression in patients with COPD [12]. There is also evidence that cigarette smoke modulates the signaling pathways that regulate ABCA1 expression in macrophages in vitro and in vivo $[12,14]$. Pulmonary abnormalities in ABCA1 expression have also been found in pneumonia caused by chlamydia pneumoniae bacteria [13, 15]. Chlamydia pneumoniae infection was demonstrated to affect cholesterol trafficking, associated with accelerating intracellular cholesterol accumulation by downregulating ABCA1 expression in mice models in vivo and human macrophage and lung epithelial cells in vitro $[13,15,16]$. However, the exact role of $A B C A 1$ in the pathogenesis of respiratory infection is currently unknown.

\section{ABCA1, cholesterol homeostasis and the link with inflammation}

Cellular cholesterol is linked with numerous inflammatory functions of the lungs [17]. Hence, the proteins involved in the process of RCT may impact the inflammatory responses elicited by overloading of free cholesterol in macrophages [18]. Understanding the functions of ABCA1 and HDL may reveal the impact of regulating cholesterol on inflammatory functions in lungs. In addition to HDL's role in RCT, HDL assists with the production of surfactant in alveolar type II cells [19], a critical cell type in COPD. Furthermore, it is known that when ABCA1 is repressed, excess cholesterol builds up in alveolar cells, damaging surfactant function and increasing the inflammatory response which has been implicated in the pathogenesis of chronic obstructive pulmonary disease (COPD), asthma and other lung diseases (reviewed in $[1,17,20]$ ).

Considering the relationship between cholesterol homeostasis and airway inflammation, the therapeutic focus has been on reducing intracellular cholesterol synthesis using cholesterol-lowering drugs, like statins [17]. There have been large clinical trials, including STATCOPE, that have tested the effectiveness of statin treatment on patients with COPD [21, 22]. Despite the benefits that were observed in prior retrospective studies, STATCOPE observed no therapeutic benefit from statin treatment in patients with COPD [21, 23, 24]. This would suggest that a different approach to restoring cholesterol balance, perhaps through alternative targets that have the potential to modulate cholesterol, and repress inflammation at the same time, such as ABCA1, warrant further investigation. This is the focus of this review.

Most studies exploring the role and function of ABCA1 have been conducted in cholesterol associated disease states such as atherosclerosis [25]. Atherosclerosis was traditionally known as a cholesterol storage disease [26]. However, it is now recognised as a chronic inflammatory disease, with evidence of excess cholesterol accumulation promoting inflammatory responses $[27,28]$. There are a number of lines of evidence from clinical and preclinical studies that link atherosclerosis and inflammation. An earlier study using mice models showed that inhibiting the expression of inflammatory mediators significantly improves the severity of atherosclerosis [29]. Patients with atherosclerosis are identified by high levels of low density lipoproteins (LDL) cholesterol in their body [30]. Regulation of LDL cholesterol homeostasis affects the innate immune system [31]. This is shown by LDL cholesterol inducing pro-inflammatory 
cytokines through activation of the toll-like receptor (TLR) pathways [32,33]. This has led the research focus to shift towards looking at the anti-inflammatory benefits of ABCA1 in atherosclerosis. ABCA1 may also exert direct anti-inflammatory actions $[34,35]$ that are independent of its impact on cholesterol homeostasis, although given the central role of cholesterol in cell survival, this independence may prove difficult to tease out.

Nevertheless, growing evidence has clearly implicated ABCA1 as a target of interest in diseases typified by inflammation. The potential anti-inflammatory effects of ABCA1 have thus led to increasing interest towards investigating the benefit of ABCA1 in inflammatory lung diseases $[12,36]$. While it is well recognised that cholesterol exerts significant regulatory control over ABCA1 expression, less well understood is the impact that inflammatory mediators themselves have on ABCA1 upregulation. Given the interaction between cholesterol homeostasis and pulmonary inflammation, the linkage represents a feasible option for therapeutic intervention with the potential to have beneficial effects in both atherosclerosis and COPD; two chronic conditions that are a common comorbidity. To highlight these potential therapeutic interactions, the aim of this review is to explore the molecular mechanisms responsible for ABCA1 expression. Notably, ABCA1 expression can be regulated via cholesterol-dependent and -independent mechanisms and the aim of the review is to explore these signaling pathways in the context of respiratory disease.

\section{Regulation of ABCA1 expression: cholesterol-dependent signaling pathways}

Cholesterol homeostasis is maintained through feedforward and feed-back mechanisms involving ABCA1 and other partners. Notably, ABCA1 expression is regulated through key signaling pathways mediated by excess cholesterol (Fig. 1), which will be described briefly below.

\section{LXR/RXR pathway}

Cholesterol in cells can be converted into oxysterols, which in turn can potently upregulate ABCA1 expression [4]. In cell types with relevance to inflammatory lung diseases (including macrophage, epithelial and smooth muscle cells (Table 1) [4, 35, 40-43]), the predominantly reported oxysterol is 25 -hydroxycholesterol $(25-\mathrm{HC})$. This naturally occurring stimulus increases the expression of ABCA1 through activation of liver X receptor (LXR) pathway $[44,45]$. LXR forms a heterodimer with retinoid X receptor (RXR), and together they form a transcription factor that binds to the promoter element in the ABCA1 gene to increase expression and ultimately the upregulation of ABCA1 protein expression [44, 45], amongst other targets. Transcription occurs upon influx of excess intracellular cholesterol, however cholesterol does not directly activate this pathway but is converted to $25-\mathrm{HC}$ [46]. While oxysterols are the ligands that activate LXR/RXR to increase ABCA1 expression, cholesterol loading triggers the increase in oxysterol production downstream of the mevalonate pathway to initiate increasing transcription of ABCA1 gene [47, 48]. Specific oxysterols can be produced de novo in the mevalonate pathway, independent of the common cholesterol derived oxysterol [49]. Cholesterol in humans is predominately synthesized de novo by the liver, initiated by acetyl coenzyme 3-hydroxy-3-methyl-glutarylcoenzyme [50]. 24(S),25-epoxycholesterol $(24,25 \mathrm{EC})$ is such an example, where it is produced from acetyl coenzyme during a gap in the mevalonate pathway [51]. Similar to other oxysterols, 24,25EC has since shown in studies to activate LXR receptors [52].

Given the important role played by LXR in this pathway, it follows that a potential therapeutic target to modulate cholesterol homeostasis is by increasing ABCA1 expression through the LXR dependent pathway [41]. To this end, a series of synthetic LXR agonists have been developed that are able to significantly increase ABCA1 expression [42]. However LXR agonist treatment outcomes have been varied with reports of adverse off-

Table 1 Currently known effects of clinical and experimental drugs on ABCA1 expression in cells in vitro

\begin{tabular}{|c|c|c|c|}
\hline Cell Type & Stimuli & $\begin{array}{l}\text { Change in } \mathrm{ABCA} 1 \\
\text { Protein Expression }\end{array}$ & References \\
\hline Macrophage Cells & $\begin{array}{l}\text { Simvastatin } \\
\text { Atorvastatin } \\
\text { TNF } \\
\text { Cholesterol/CD } \\
\text { Oxysterol ( } 25 \text { Hydroxyl Cholesterol) } \\
\text { Cigarette Smoke Extract }\end{array}$ & $\begin{array}{l}\downarrow \\
\downarrow \\
\downarrow / \uparrow \\
\uparrow \\
\uparrow \\
\downarrow\end{array}$ & $\begin{array}{l}{[37,38]} \\
{[37,38]} \\
{[16,39]} \\
{[40]} \\
{[41]} \\
{[12]}\end{array}$ \\
\hline Bronchial Epithelial Cells & $\begin{array}{l}\text { Simvastatin } \\
\text { Atorvastatin } \\
\text { TNF } \\
\text { Cholesterol/CD } \\
\text { Oxysterol (25 Hydroxyl Cholesterol) }\end{array}$ & $\begin{array}{l}\mathrm{ns} \\
\mathrm{ns} \\
\uparrow \\
\uparrow \\
\uparrow\end{array}$ & $\begin{array}{l}{[4]} \\
{[4]} \\
{[4]} \\
{[4]} \\
{[4]}\end{array}$ \\
\hline Airway Smooth Muscle Cells & Cholesterol/CD & $\uparrow$ & [42] \\
\hline
\end{tabular}




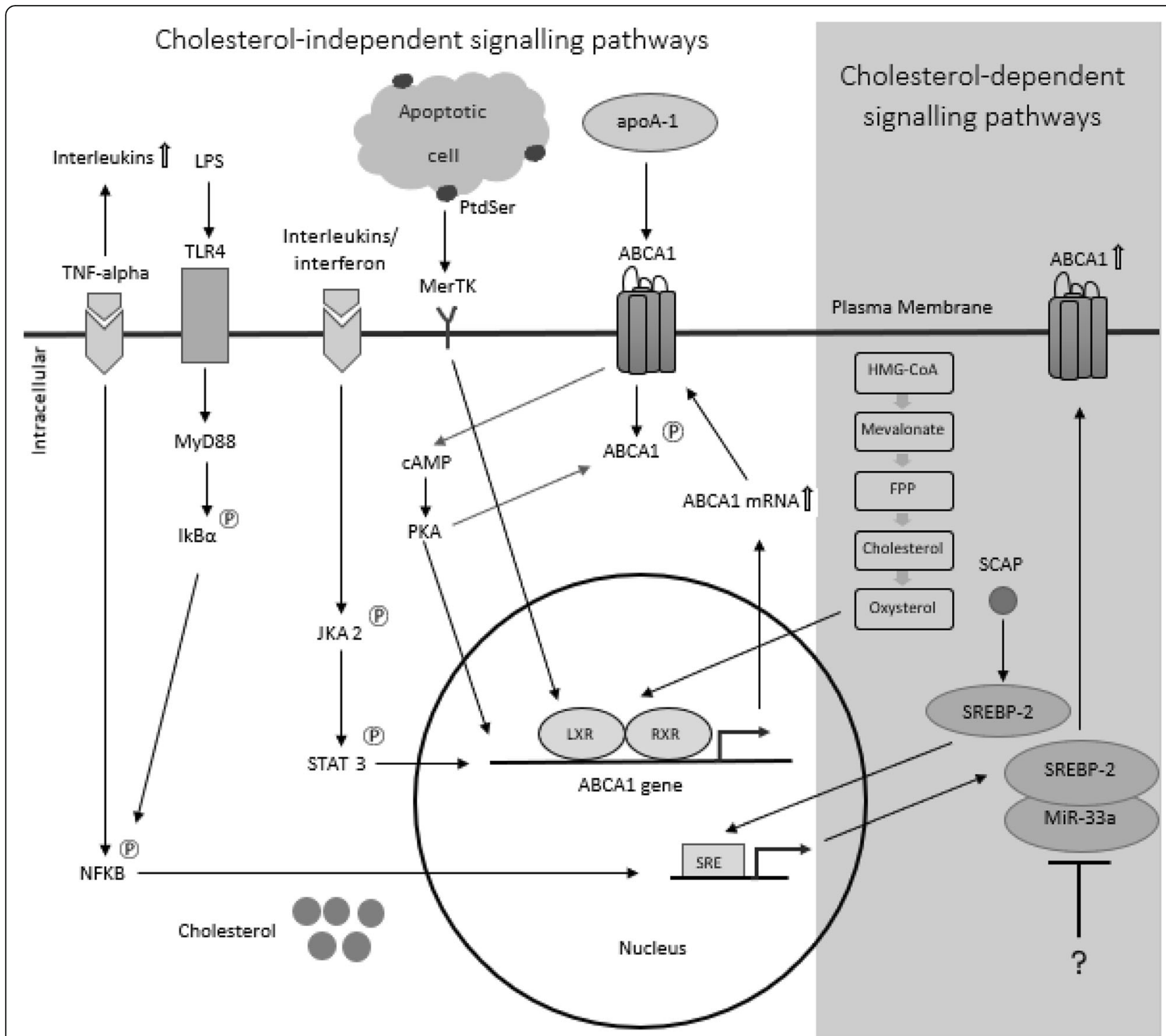

Fig. 1 ABCA1 cell signaling pathways. The cholesterol-dependent signaling pathways which regulate ABCA1 include the LXR/RXR and SREBP-2 pathway. These two pathways are activated in response to changes in intracellular cholesterol levels by oxysterols and SREBP-2 molecules which target the transcriptions factors, LXR/RXR and SREBP-2, respectively. The cholesterol-independent signaling pathways associated with ABCA1 regulation include the NF-KB, TLR4/Myleoid88, JAK2/STAT3, CAMP/PKA, apoptosis pathways involved in regulating inflammatory responses

target effects, including increased fatty acid, triglyceride synthesis and hepatic steatosis [53-55]. Recently, there has been increasing interest in the possibility that LXR $\alpha$, an isoform of LXR, is the primary cause for adverse effects of conventional LXR ligands [56]. This has created interest in the development of LXR $\beta$-specific drugs that are thought not to generate such adverse effects.

\section{SREBP-2 pathway}

Another pathway involved in the regulation of cellular cholesterol homeostasis is mediated by the sterol regulatory element binding protein 2 (SREBP-2) transcription factor [44]. SREBP-2 regulates ABCA1 independently of the LXR pathway, and, unlike the LXR pathway activation, SREBP-2 activation can decrease ABCA1 expression [46, $56,57]$. SREBP-2 activation is dependent on the SREBP cleavage activating protein (SCAP) protein, which has a sterol sensing domain capable of sensing cellular cholesterol levels [46]. When intracellular cholesterol levels are low, SCAP escorts SREBP-2 to the Golgi for activation before being translocated to the sterol regulatory element (SRE) in the nucleus to promote transcription of different target genes as well as SREBP-2 itself [33]. Located within intron 16 of SREBP-2 is microRNA-33a (miR-33a), which is co-transcribed with SREBP-2 [33, 58]. The miR-33a has been shown to inhibit ABCA1 expression in mice 
pancreatic islets ex vivo and human macrophages in vitro [58-60]. Recently, it has been demonstrated that inhibition of miR-33a in mice hepatic tissue and macrophages in vivo leads to an increased expression of the miR-33a target gene ABCA1 [61, 62]. Increasing ABCA1 expression by inhibiting miR-33a allows ABCA1 target treatment to bypass the adverse effects of current treatments that activate the LXR pathway [62].

\section{Regulation of $A B C A 1$ expression: cholesterol-independent signaling pathways}

Recent investigations have revealed that a number of inflammatory mediators and noxious exposures (such as cigarette smoke) that drive lung disease also have an impact on ABCA1 expression. Clinically-used and experimental drugs also target ABCA1, with some key in vitro studies performed in cells with relevance to respiratory disease listed in Table 1. These changes to ABCA1 expression are regulated by signaling (Fig. 1) (as detailed below), some of which are subject to cross-talk.

\section{TNF}

Tumour Necrosis Factor (TNF) is a proinflammatory cytokine that is highly expressed in patients with COPD [63]. TNF is known to activate many signaling pathways of which some have previously shown to induce changes in ABCA1 expression [64]. These pathways include the nuclear factor- $\mathrm{\kappa B}(\mathrm{NF}-\mathrm{\kappa B})$, sterol regulatory element binding protein 2 (SREBP-2) and janus kinase 2/signal transducer 3 (JAK2/STAT3) [65-67]. With numerous pathways and molecular partners involved, studies have shown that TNF stimulation can result in different impacts on ABCA1 expression depending on the cell line $[4,16,39,68]$. For example, TNF stimulation can increase ABCA1 expression via the canonical NF- $\mathrm{kB}$ pathway [69]. However, activation of NF- $\mathrm{kB}$ induced by TNF also upregulates the mRNA levels of miR-33a by targeting its host gene SREBP-2 in macrophages in vitro and mice in vivo [58]. As increased expression of miR-33a is associated with repressed $A B C A 1$ expression, increasing TNF in this context will result in decreased ABCA1 expression [70]. We have recently shown that TNF increases $A B C A 1$ protein upregulation in BEAS-2B epithelial cells in vitro [4], however to date, the molecular mechanisms for these findings are unknown. Interestingly, studies performed in parallel in another lung epithelial cell line, A549 in vitro, indicated that TNF did not increase ABCA1 protein in these cells [4]. Perhaps the difference in impact of TNF on ABCA1 within the two lung epithelial cell lines, used commonly as cellular models of respiratory inflammation, are the different contribution of miR-33a or other known ABCA1 regulators. Further studies are warranted to establish the mechanisms involved.

\section{TLR4/Myeloid88 pathway}

Toll like receptor 4 (TLR4) is a primary source of innate immune system defence [71]. This protein is expressed in macrophages and lung bronchial epithelial cells, two key cell types driving airway inflammation [72]. The major cause of airway inflammation in patients with COPD is cigarette smoke [72]. Notably, cigarette smoke exposure (CSE) results in an increase in lipopolysaccharide (LPS)-induced TLR4 expression shown in primary small airway epithelial cells in vitro and mice in vivo [72, 73]. The LPS dependent increase in TLR4 activates its downstream adaptor molecule Myeloid88 that transduces TLR4 signaling to the NF- $\kappa B$ inhibitor, I $\kappa B \alpha$ [74]. Phosphorylation of I $\mathrm{B} \alpha$ allows NF- $\mathrm{kB}$ to translocate into the nucleus [75], ultimately activating inflammatory genes responsible for encoding proinflammatory cytokines like TNF, while also promoting the expression of miR33a which reduces ABCA1 expression $[69,76]$. The effect of cigarette smoke on the TLR4/Myeloid88 pathway was explored by exposing human macrophage THP-1 cells in vitro and mice macrophages in vivo to CSE $[10,12,14]$. The results showed that ABCA1 expression was significantly downregulated by CSE exposure in vitro and in vivo $[10,12,14]$.

\section{CAMP/PKA pathway}

The cyclic adenosine monophosphate (cAMP)/protein kinase A (PKA) pathway is responsible for regulating multiple cellular functions, including anti-inflammatory responses [53]. Activation of cAMP/PKA pathway reduces inflammation by inhibiting NF-kB, preventing the reduction of ABCA1 and increased pro-inflammatory cytokines caused by NF-кB $[69,77]$. ABCA1 expression is also regulated both transcriptionally and post-translationally by the cAMP/PKA pathway [55]. Transcriptionally, cAMP induces an increase in ABCA1 expression and its mediated reverse cholesterol transport [55, 78]. Prior studies have shown that stimulating human fibroblasts in vitro and murine macrophages in vivo with a 8-bromo-cAMP analog activated the cAMP/PKA pathway $[8,79]$. Early studies performed on human macrophages were, however, unable to show a significant increase in $A B C A 1$ expression via activation of the cAMP/PKA pathway [40, 80, 81]. In contrast, a recent study performed by Liao et al. showed that stimulating human THP-1 macrophage cells with intermedin, a calcitonin family peptide, significantly increased ABCA1 expression and cholesterol efflux through the cAMP/PKA pathway [23]. It is important to note that the impact of cAMP on ABCA1 expression depends on the species used for the study, as there are key differences in the $5^{\prime}$-promoter element of the murine and human $A B C A 1$ gene whereby the functional cAMP response element (CRE) in murine $\mathrm{ABCA} 1$ gene promoter is not present in the first intron of the human promoter $[82,83]$. 
However, while transcriptional regulation differs, cells from both human and mice are responsive to cAMP, albeit via dissimilar mechanisms. Post-translationally, the upregulation of ABCA1 phosphorylation and cholesterol efflux in this signaling cascade is initiated when apoA-1 interacts with ABCA1 during the process of reverse cholesterol transport [78]. The interaction between apoA-1 and ABCA1 activates heterotrimeric $\mathrm{G}$ proteins and adenylyl cyclase to produce cAMP, consequently activating PKA, a direct downstream target of cAMP $[43,78,84]$. PKA then increases phosphorylation of ABCA1, which has been shown by previous studies to significantly increase ABCA1 expression and cholesterol efflux in macrophage cells $[78,85]$. Whether upregulation of ABCA1 by the cAMP/PKA pathway occurs in the context of inflammatory lung diseases warrants further investigation, especially since cAMP-elevating agents (e.g. $\beta_{2}$-adrenergic receptor agonists and phosphodiesterase inhibitors) are widely used treatments in respiratory medicine today.

\section{JAK2/STAT3 pathway}

Signal transducer and activator of transcription 3 (STAT3) plays a complex role in regulating inflammation that occurs with airway injury [86]. Cigarette smoke is associated with the occurrence of airway injury and inflammation, and can also activate STAT3 in the lungs $[86,87]$. While the exact role of STAT3 in inflammatory lung diseases is relatively poorly understood, it is known that the absence of STAT3 expression impairs the innate anti-inflammatory response of the lungs [86], suggesting that the presence of STAT3 is important in reducing lung inflammation. Thus far, evidence has shown that STAT3 activation as a result of ABCA1 and apoA-1 interaction produces an anti-inflammatory effect [88]. Similar anti-inflammatory effects were shown by proinflammatory cytokines, interleukins and interferons activation of the janus kinase 2 (JAK2)/STAT3 pathway [89, 90]. A known cytokine that activates this pathway is interleukin 6 (IL-6), with IL-6 expression promoted by inflammatory markers of COPD like TNF [89, 91]. The initial signaling molecule which is activated upon apoA-1 and ABCA1 interaction or by IL- 6 cytokine is JAK2 $[88,92]$. Upon activation of JAK2, it undergoes autophosphorylation, before phosphorylating its downstream target STAT3 [92, 93]. In human and mouse macrophages, phosphorylated STAT3 binds onto the CRE site located on the first intron of the human and murine ABCA1 gene to increase the gene expression of ABCA1 [90, 94].

\section{Apoptosis increases $A B C A 1$ expression}

During acute and chronic airway inflammation there is a significant increase in immune and structural cells that undergo apoptosis [95]. The clearance of cell apoptosis in the lungs is primarily regulated by airway macrophages in a process called efferocytosis [95]. Apoptotic cells have previously been shown to be directly associated with an increase in ABCA1 expression in macrophages $[96,97]$. Apoptotic cells contain phosphatidylserine (PtdSer) that acts like a recognition signal for phagocytes, binding onto cell surface receptors on macrophages, like mer tyrosine kinase (MerTK) [95, 97]. During efferocytosis regulated by MerTK in pulmonary tissue, the LXR pathway is activated; thus expression of ABCA1 is upregulated [90]. With the increased apoptosis that occurs in inflammatory lung diseases like COPD, the likely corollary is that ABCA1 expression should be increased; however, this prediction does not hold true because the process of efferocytosis in patients with COPD is dysregulated [98]. The exact mechanism underlying the defect of efferocytosis in COPD is unknown, however, it is speculated to be linked to alterations in expression and function of the PtdSer receptors such as MerTK [95, 99]. Hence, additional studies exploring the molecular mechanisms behind dysregulated efferocytosis in COPD are needed to identify what the potential effect of functional alterations in MerTK has on ABCA1 expression.

Recent studies have reported a pathway regulated by the phagocytic receptor brain specific angiogenesis inhibitor 1 (BAI1), operates in a similar manner to the way in which MerTK recognises the PtdSer on apoptotic cells [100]. In brief, BAI1 activates its downstream signaling mediator Ras-related C3 botulinum toxin substrate 1 (RAC1) upon contact with PtdSer to promote ABCA1 transcription independent of the LXR pathway [100]. It is currently unclear whether this pathway is present in pulmonary tissue. Thus, further studies examining the effect of apoptosis on ABCA1 expression in lung macrophages are warranted.

\section{ApoA-1 interaction with $A B C A 1$}

ApoA-1 is an acceptor for cellular cholesterol from peripheral cells that directly interacts with ABCA1 to forms nascent lipid-poor HDL [101]. Murphy et al. showed that HDL formed from the interaction between apoA-1 and ABCA1 had anti-inflammatory effects [102]. It is likely that the anti-inflammatory properties of apoA-1 are directly associated with regulation of the ABCA1 signaling pathways, cAMP/PKA and JAK2/STAT3 [78, 88]. As outlined above, both of these signaling pathways are known to upregulate ABCA1 expression, with increased ABCA1 expression correlated with increase in HDL [20]. The signaling pathways involved with the regulation of ABCA1 expression are hence key in mediating the antiinflammatory properties of HDL.

Intriguingly, apoA-1 represses LPS-induced proinflammatory cytokine production via the TLR4/myeloid88 pathway in macrophages [34]. This was linked to 
reduction in mRNA stability of proinflammatory mediators through the actions of the destabilising RNA binding protein, tristetraprolin (TTP) [34]. While it is unclear as to the exact mechanism by which the interaction between ABCA1 and apoA-1 induce the TTP-mediated antiinflammatory effect, Yin et al. reported that the effect of apoA-1 on TTP was significantly diminished when ABCA1 expression was silenced [34]. Taken together, these studies underscore the promise of ApoA-1 as a beneficial target in respiratory disease. However, the cost of purified apoA-1 and recombinant apoA-1 may prove prohibitive to further investigation. Synthetic analogs of apoA-1, known as apoA-1 mimetics, have been developed that offer a cost-effective solution [103]. Excitingly, ApoA-1 mimetics 5A and 4F administered intravenously and intratracheally have been shown to exhibit anti-inflammatory and antioxidant effects in human coronary artery cells in vitro and mice in vivo through interaction with ABCA1 [103, 104]. Further investigations are warranted.

\section{Effect of current medications in pulmonary diseases on ABCA1 expression}

Current pharmacological treatments for people with respiratory disease include the use of corticosteroids, bronchodilators (such as $\beta_{2}$-adrenergic receptor agonist) and phosphodiesterase inhibitors. Although some studies have examined the impact of current respiratory medications on ABCA1 expression, there is much scope for further investigation. The effect of these medicines on the signaling pathways regulating ABCA1 expression will be outlined below.

\section{Corticosteroids}

To date, there have been limited studies aimed at examining the effect of steroids on ABCA1 expression. While there is no evidence of a glucocorticoid response element in the $\mathrm{ABCA} 1$ promoter, non-cis mediated transcriptional regulation of $\mathrm{ABCA} 1$ has been shown to exist in macrophages $[105,106]$. The steroid dexamethasone decreased ABCA1 expression through a LXR-independent pathway in macrophages in vitro [106].

\section{Bronchodilators}

$\beta_{2}$-adrenergic receptor agonists are commonly used bronchodilators for treating lung diseases such as COPD or asthma [107]. The mechanism by which $\beta_{2}$-agonists promote bronchodilator effects in the lungs is thought to occur via cAMP/PKA-dependent reduction in intracellular calcium [108], although other pathways may exist. Activation of the cAMP/PKA pathway is the result of increased intracellular cAMP after $\beta_{2}$-agonists treatment [109]. As outlined in a previous section, it has been established that CAMP induces upregulation of ABCA1 expression in human macrophages [110]. Thus, in addition to the bronchodilator effects of $\beta_{2}$-agonists treatment, anti-inflammatory properties of $\beta_{2}$-agonists may be associated with ABCA1 mediated suppression of inflammatory responses in the lungs.

\section{Phosphodiesterase inhibitors}

Type 4 phosphodiesterase (PDE4) inhibitors are a treatment option in COPD. Similar to the effect of $\beta_{2}$-agonists, PDE4 inhibitors exhibit multiple benefits which include reducing inflammation and eliciting airway smooth muscle relaxation via the cAMP/PKA pathway [18]. The PDE4 selective inhibitor, rolipram, has been shown to increase intracellular cAMP which upregulates ABCA1 expression and apoA-1-mediated cholesterol efflux in mouse and human macrophages [111].

\section{$A B C A 1$ as an alternative biological target for the treatment of lung inflammation \\ Statins}

Statins were postulated as possible treatment for inflammatory lung diseases including COPD. However, clinical trials like STATCOPE were shown to have an overall insignificant impact on patient outcomes [21, 112, 113]. Previous studies have looked at whether the reason behind the statins' inability to significantly reduce inflammation during pulmonary exacerbation is linked with ABCA1 being downregulated as a result of statin treatment $[1,4,37]$. We recently showed that in human lung epithelial cell lines in vitro, both simvastatin and atorvastatin did not significantly impact on ABCA1 expression (Table 1) [4]. In human macrophage cells in vitro, however, Niesor et al. showed that simvastatin and atorvastatin reduced $A B C A 1$ expression and increased miR33, supporting the possibility that a repressive effect on ABCA1mediated anti-inflammatory functions could have played a role in the equivocal outcomes shown in STATCOPE [37]. It is plausible that the different results in these cell lines were due to cell type specificity. Hence, by testing this hypothesis on other pulmonary cell lines, like airway smooth muscle cells, we would improve our understanding of the effect of statins on ABCA1 expression more broadly, and whether combination therapy to ameliorate possible statininduced $A B C A 1$ downregulation is suitable.

\section{LXR agonists}

Given that the LXR transcription factor is a potent inducer of ABCA1 expression coupled with evidence of anti-inflammatory impact [11], it follows that LXR agonists would be strong candidates as potential therapeutics for treatment of inflammatory lung disease. This was supported by recent studies using intranasal administration of LXR agonists (T0901317 or GW3965) that showed significant attenuation of pro-inflammatory 
cytokines in mice in vivo and lung epithelial cells in vitro $[114,115]$. However, as outlined, currently available LXR ligands target both LXR isoforms, leading to undesirable side effects on lipid parameters $[116,117]$. These include increased plasma fatty acid and triglycerides, which are known risk factors of COPD [118-120]. Early LXR agonists, such as GW3965, have also failed to completely repress inflammatory cytokine production from alveolar macrophages in vitro [121]. The adverse effects of synthetic LXR agonist treatment, including elevated triglyceride levels and hepatoxicity, are thought due to LXR $\alpha$ activation [117]. Thus, development of LXR $\beta$-selective agonists are currently under clinical investigation to mitigate against hepatic lipogenesis.

\section{Conclusions}

In recent years, our understanding of the role and function of $\mathrm{ABCA} 1$ has evolved from the traditional function in maintaining cellular cholesterol homeostasis to include its potent anti-inflammatory function. This has led to the possibility of exploiting known and novel signaling pathways to upregulate ABCA1 expression in a number of chronic disease settings. Notably, signaling pathways implicated in inflammatory responses are responsible for regulating ABCA1 (transcriptionally or post-translationally) and its ability to repress inflammation exists. Currently unknown is the extent of the therapeutic benefit that may be achieved by targeting ABCA1 in inflammatory lung diseases like COPD. Despite the primary focus on the potential of $\mathrm{ABCA1}$ as a therapeutic target in atherosclerosis, its dual role in repressing inflammation while maintaining cholesterol homeostasis represents a promising therapeutic target for inflammatory lung diseases in the future.

\begin{abstract}
Abbreviations
ABCA1: ATP binding cassette A1; apoA-1: Apolipoprotein A1; BAl1: Brain specific angiogenesis inhibitor 1; CAMP: Cyclic adenosine monophosphate; COPD: Chronic obstructive pulmonary disease; CRE: Camp response element; CSE: Cigarette smoke extract; 25-HC: 25-hydroxycholesterol; HDL: High density lipoprotein; IL: Interleukin; JAK2: Janus kinase 2;

LPS: Lipopolysaccharide; LXR: Liver X receptor; MerTK: Mer tyrosine kinase; miR-33: Micro RNA-33; NF-kB: Nuclear factor kB; PKA: Protein kinase A; PtdSer: Phosphatidylserine; RAC1: Ras-related C3 botulinum toxin substrate 1; RCT: Reverse cholesterol transport; RXR: Retinoid X receptor; SCAP: SREBP cleavage activating protein; SRE: Sterol regulatory element; SREBP-2: Sterol regulatory element binding protein 2; STAT3: Signal transducer 3; TLR4: Toll like receptor 4; TNF: Tumour necrosis factor; TTP: Tristetraprolin
\end{abstract}

\section{Acknowledgements}

The authors wish to acknowledge the generous support of the Ernest Heine Family Foundation, and Mrs. Janice Gibson and the late Mr. Freddie Gibson in establishing the Woolcock Emphysema Centre.

\section{Authors' contributions}

$\mathrm{PH}$ drafted the article and prepared the figures and table. ICG provided critical feedback on drafts. PH and AJA both edited the final article while AJA prepared the review for submission. All authors read and approved the final manuscript.

\section{Funding}

$\mathrm{PH}$ is supported by an Australian Government Research Training Program Stipend through UTS. PH and AJA are supported by National Health and Medical Research Council and the Woolcock Emphysema Centre.

\section{Availability of data and materials \\ Not applicable.}

\section{Ethics approval and consent to participate}

Not applicable.

\section{Consent for publication}

All authors read and approved the final manuscript.

\section{Competing interests}

The authors declare that they have no competing interests.

\section{Author details}

${ }^{1}$ Woolcock Emphysema Centre, Woolcock Institute of Medical Research, University of Sydney, Sydney, NSW, Australia. ${ }^{2}$ School of Life Sciences, Faculty of Science, University of Technology Sydney, Sydney, NSW, Australia. ${ }^{3}$ Sydney Pharmacy School, Faculty of Medicine and Health, University of Sydney, Sydney, NSW 2006, Australia.

Received: 5 June 2020 Accepted: 21 September 2020

Published online: 25 September 2020

\section{References}

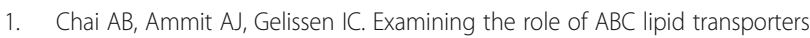
in pulmonary lipid homeostasis and inflammation. Respir Res. 2017;18:41.

2. Soumian S, Albrecht C, Davies A, Gibbs R. ABCA1 and atherosclerosis. Vasc Med. 2005;10:109-19.

3. Yvan-Charvet $L$, Wang $N$, Tall AR. Role of HDL, ABCA1, and ABCG1 transporters in cholesterol efflux and immune responses. Arterioscler Thromb Vasc Biol. 2010;30:139-43.

4. Babashamsi MM, Koukhaloo SZ, Halalkhor S, Salimi A, Babashamsi M. ABCA1 and metabolic syndrome; a review of the ABCA1 role in $\mathrm{HDL}-\mathrm{VLDL}$ production, insulin-glucose homeostasis, inflammation and obesity. Diabetes Metab Syndr. 2019;13:1529-34.

5. Yang S-T, Kreutzberger AJB, Lee J, Kiessling V, Tamm LK. The role of cholesterol in membrane fusion. Chem Phys Lipids. 2016;199:136-43.

6. Miller NE. HDL metabolism and its role in lipid transport. Eur Heart J. 1990; 11(Suppl H):1-3.

7. Marques LR, Diniz TA, Antunes BM, Rossi FE, Caperuto EC, Lira FS, Gonçalves DC. Reverse cholesterol transport: molecular mechanisms and the nonmedical approach to enhance HDL cholesterol. Front Physiol. 2018;9.

8. Oram JF. Tangier disease and ABCA1. Biochim Biophys Acta (BBA). 2000; 1529:321-30.

9. Aiello RJ, Brees D, Francone OL. ABCA1-Deficient Mice. Arterioscler Thromb Vasc Biol. 2003:23:972-80.

10. Sklepkiewicz PL, Lemaitre V, Zelonina T, Westerterp M, Tall A, D'Armiento J. Abstract 551: the dual effect of cigarette smoke on macrophage Abca1dependent cholesterol efflux and protease production leads to decreased collagen and increased necrosis in plaques of ApoE deficient mice. Arterioscler Thromb Vasc Biol. 2013;33:A551.

11. Bochem AE, van der Valk FM, Tolani S, Stroes ES, Westerterp M, Tall AR. Increased systemic and plaque inflammation in ABCA1 mutation carriers with attenuation by statins. Arterioscler Thromb Vasc Biol. 2015;35:1663-9.

12. Sonett J, Goldklang M, Sklepkiewicz P, Gerber A, Trischler J, Zelonina T, Westerterp M, Lemaitre V, Okada Y, D’Armiento J. A critical role for ABC transporters in persistent lung inflammation in the development of emphysema after smoke exposure. FASEB J. 2018;32:6724-36.

13. Korhonen JT, Olkkonen VM, Lahesmaa R, Puolakkainen M. ABC-cassette transporter 1 (ABCA1) expression in epithelial cells in chlamydia pneumoniae infection. Microb Pathog. 2013;61-62:57-61.

14. Song W, Wang W, Dou L-Y, Wang Y, Xu Y, Chen L-F, Yan X-W. The implication of cigarette smoking and cessation on macrophage cholesterol efflux in coronary artery disease patients. J Lipid Res. 2015;56:682-91.

15. Edvinsson M, Tallkvist J, Nyström-Rosander C, Ilbäck N-G. Cholesterol uptake in the mouse aorta increases during chlamydia pneumoniae infection. Pathogens Disease. 2017;75. 
16. Liu W, He P, Cheng B, Mei CL, Wang YF, Wan JJ. Chlamydia pneumoniae disturbs cholesterol homeostasis in human THP-1 macrophages via JNKPPARy dependent signal transduction pathways. Microbes Infect. 2010;12: 1226-35.

17. Gowdy KM, Fessler MB. Emerging roles for cholesterol and lipoproteins in lung disease. Pulm Pharmacol Ther. 2013;26:430-7.

18. Brown WM. Treating COPD with PDE 4 inhibitors. Int J Chronic Obstruct Pulmon Dis. 2007;2:517-33.

19. Kolleck I, Sinha P, Rustow B. Vitamin E as an antioxidant of the lung: mechanisms of vitamin E delivery to alveolar type II cells. Am J Respir Crit Care Med. 2002;166:S62-6.

20. Attie AD, Kastelein JP, Hayden MR. Pivotal role of ABCA1 in reverse cholesterol transport influencing HDL levels and susceptibility to atherosclerosis. J Lipid Res. 2001;42:1717-26.

21. Criner GJ, Connett JE, Aaron SD, Albert RK, Bailey WC, Casaburi R, Cooper JAD, Curtis JL, Dransfield MT, Han MK, et al. Simvastatin for the prevention of exacerbations in moderate-to-severe COPD. N Engl J Med. 2014;370: 2201-10.

22. Ingebrigtsen TS, Marott JL, Nordestgaard BG, Lange P, Hallas J, Vestbo J. Statin use and exacerbations in individuals with chronic obstructive pulmonary disease. Thorax. 2015;70:33-40.

23. Liao H, Wan S, Zhang X, Shi D, Zhu X, Chen X. Intermedin Ameliorates Atherosclerosis by Increasing Cholesterol Efflux Through the CAMP-PKA Pathway in Macrophage RAW264.7 Cell Line. Med Sci Monit. 2017;23: 5462-71.

24. Wang MT, Lo YW, Tsai CL, Chang LC, Malone DC, Chu CL, Liou JT. Statin use and risk of COPD exacerbation requiring hospitalization. Am J Med. 2013; 126:598-606.e592.

25. Singaraja RR, Fievet C, Castro G, James ER, Hennuyer N, Clee SM, Bissada N, Choy JC, Fruchart JC, MCManus BM, et al. Increased ABCA1 activity protects against atherosclerosis. J Clin Invest. 2002;110:35-42.

26. Libby P. Inflammation in atherosclerosis. Arterioscler Thromb Vasc Biol. 2012 32:2045-51.

27. Conti P, Shaik-Dasthagirisaeb Y. Atherosclerosis: a chronic inflammatory disease mediated by mast cells. Cent Eur J Immunol. 2015;40:380-6.

28. Tsoupras A, Lordan R, Zabetakis I. Inflammation, not cholesterol, Is a Cause of Chronic Disease. Nutrients. 2018;10:604

29. Kirii H, Niwa T, Yamada Y, Wada H, Saito K, Iwakura Y, Asano M, Moriwaki H, Seishima M. Lack of interleukin-1 beta decreases the severity of atherosclerosis in ApoE-deficient mice. Arterioscler Thromb Vasc Biol. 2003; 23:656-60.

30. Fu H, Tang $Y Y$, Ouyang XP, Tang SL, Su H, Li X, Huang LP, He M, LV YC, He $P P$, et al. Interleukin-27 inhibits foam cell formation by promoting macrophage ABCA1 expression through JAK2/STAT3 pathway. Biochem Biophys Res Commun. 2014;452:881-7.

31. Jukema RA, Ahmed TAN, Tardif J-C. Does low-density lipoprotein cholesterol induce inflammation? If so, does it matter? Current insights and future perspectives for novel therapies. BMC Med. 2019;17:197.

32. Stewart CR, Stuart LM, Wilkinson K, van Gils JM, Deng J, Halle A, Rayner KJ, Boyer L, Zhong R, Frazier WA, et al. CD36 ligands promote sterile inflammation through assembly of a toll-like receptor 4 and 6 heterodimer. Nat Immunol. 2010;11:155-61.

33. Duewell $\mathrm{P}$, Kono H, Rayner KJ, Sirois CM, Vladimer G, Bauernfeind FG, Abela GS, Franchi L, Nuñez G, Schnurr M, et al. NLRP3 inflammasomes are required for atherogenesis and activated by cholesterol crystals. Nature. 2010;464: 1357-61.

34. Yin K, Deng X, Mo Z-C, Zhao G-J, Jiang J, Cui L-B, Tan C-Z, Wen G-B, Fu Y, Tang C-K. Tristetraprolin-dependent post-transcriptional regulation of inflammatory cytokine mRNA expression by apolipoprotein A-I: role of ATPbinding membrane cassette transporter a1 and signal transducer and activator of transcription 3. J Biol Chem. 2011;286:13834-45

35. Castiglioni S, Monti M, Buscherini GA, Arnaboldi L, Canavesi M, Corsini A, Bellosta S. The dataset describes: phenotypic changes induced by cholesterol loading in smooth muscle cells isolated from the aortae of C57BL/6 mice. Data Brief. 2018;16:334-40.

36. Yin K, Liao D-f, Tang C-k. ATP-binding membrane cassette transporter A (ABCA1): a possible link between inflammation and reverse cholestero transport. Mol Med (Cambridge, Mass). 2010;16:438-49.

37. Niesor EJ, Schwartz GG, Perez A, Stauffer A, Durrwell A, Bucklar-Suchankova G, Benghozi R, Abt M, Kallend D. Statin-induced decrease in ATP-binding cassette transporter A1 expression via microRNA33 induction may counteract cholesterol efflux to high-density lipoprotein. Cardiovasc Drugs Ther. 2015;29:7-14.

38. Wong J, Quinn CM, Gelissen IC, Jessup W, Brown AJ. The effect of statins on $A B C A 1$ and $A B C G 1$ expression in human macrophages is influenced by cellular cholesterol levels and extent of differentiation. Atherosclerosis. 2008. 196:180-9.

39. Gerbod-Giannone M-C, Li Y, Holleboom A, Han S, Hsu L-C, Tabas I, Tall AR. TNFa induces ABCA1 through NF-KB in macrophages and in phagocytes ingesting apoptotic cells. Proc Natl Acad Sci U S A. 2006;103:3112-7.

40. Kiss RS, Maric J, Marcel YL. Lipid efflux in human and mouse macrophagic cells: evidence for differential regulation of phospholipid and cholesterol efflux. J Lipid Res. 2005;46:1877-87.

41. Dai XY, Ou X, Hao XR, Cao DL, Tang YL, Hu YW, Li XX, Tang CK. The effect of T0901317 on ATP-binding cassette transporter A1 and Niemann-pick type C1 in apoE-/- mice. J Cardiovasc Pharmacol. 2008:51:467-75.

42. Delvecchio CJ, Bilan P, Nair P, Capone JP. LXR-induced reverse cholesterol transport in human airway smooth muscle is mediated exclusively by ABCA1. Am J Phys Lung Cell Mol Phys. 2008;295:L949-57.

43. Beyea MM, Reaume S, Sawyez CG, Edwards JY, O'Neil C, Hegele RA, Pickering JG, Huff MW. The oxysterol 24(s),25-epoxycholesterol attenuates human smooth muscle-derived foam cell formation via reduced lowdensity lipoprotein uptake and enhanced cholesterol efflux. J Am Heart Assoc. 2012;1:e000810.

44. Wong J, Quinn CM, Brown AJ. SREBP-2 positively regulates transcription of the cholesterol efflux gene, ABCA1, by generating oxysterol ligands for LXR. Biochem J. 2006:400:485-91.

45. Wang N, Tall AR. Regulation and mechanisms of ATP-binding cassette transporter A1-mediated cellular cholesterol efflux. Arterioscler Thromb Vasc Biol. 2003;23:1178-84.

46. Muse ED, Yu S, Edillor CR, Tao J, Spann NJ, Troutman TD, Seidman JS, Henke A, Roland JT, Ozeki KA, et al. Cell-specific discrimination of desmosterol and desmosterol mimetics confers selective regulation of LXR and SREBP in macrophages. Proc Natl Acad Sci. 2018;115:E4680-9.

47. Olsen BN, Schlesinger PH, Ory DS, Baker NA. Side-chain oxysterols: from cells to membranes to molecules. Biochim Biophys Acta Biomembr. 2012:1818:330-6.

48. Gabor KA, Fessler MB. Roles of the Mevalonate pathway and cholesterol trafficking in pulmonary host defense. Curr Mol Pharmacol. 2017;10:27-45.

49. Wong J, Quinn CM, Brown AJ. Synthesis of the oxysterol, 24(S), 25epoxycholesterol, parallels cholesterol production and may protect against cellular accumulation of newly-synthesized cholesterol. Lipids Health Dis. 2007:6:10.

50. Pietrocola F, Galluzzi L, Bravo-San Pedro JM, Madeo F, Kroemer G. Acetyl coenzyme A: a central metabolite and second messenger. Cell Metab. 2015; 21:805-21.

51. Nelson JA, Steckbeck SR, Spencer TA. Biosynthesis of 24,25-epoxycholesterol from squalene 2,3;22,23-dioxide. J Biol Chem. 1981:256:1067-8.

52. Lehmann JM, Kliewer SA, Moore LB, Smith-Oliver TA, Oliver BB, Su JL, Sundseth SS, Winegar DA, Blanchard DE, Spencer TA, Willson TM. Activation of the nuclear receptor LXR by oxysterols defines a new hormone response pathway. J Biol Chem. 1997:272:3137-40.

53. Kirchgessner TG, Sleph P, Ostrowski J, Lupisella J, Ryan CS, Liu X, Fernando G, Grimm D, Shipkova P, Zhang R, et al. Beneficial and adverse effects of an LXR agonist on human lipid and lipoprotein metabolism and circulating neutrophils. Cell Metab. 2016;24:223-33.

54. Lund EG, Peterson LB, Adams AD, Lam M-HN, Burton CA, Chin J, Guo Q, Huang S, Latham M, Lopez JC, et al. Different roles of liver $X$ receptor $a$ and $\beta$ in lipid metabolism: effects of an a-selective and a dual agonist in mice deficient in each subtype. Biochem Pharmacol. 2006;71:453-63.

55. Luu W, Sharpe LJ, Gelissen IC, Brown AJ. The role of signalling in cellular cholesterol homeostasis. IUBMB Life. 2013;65:675-84.

56. Tamura S, Okada M, Kato S, Shinoda Y, Shioda N, Fukunaga K, Ui-Tei K, Ueda M. Ouabagenin is a naturally occurring LXR ligand without causing hepatic steatosis as a side effect. Sci Rep. 2018:8:2305

57. Fernandez-Hernando C, Moore KJ. MicroRNA modulation of cholesterol homeostasis. Arterioscler Thromb Vasc Biol. 2011;31:2378-82.

58. Mao M, Lei H, Liu Q, Chen Y, Zhao L, Li Q, Luo S, Zuo Z, He Q, Huang W, et al. Effects of miR-33a-5P on ABCA1/G1-mediated cholesterol efflux under inflammatory stress in THP-1 macrophages. PLoS One. 2014;9:e109722.

59. Barna BP, McPeek M, Malur A, Fessler MB, Wingard CJ, Dobbs L, Verbanac KM, Bowling M, Judson MA, Thomassen MJ. Elevated MicroRNA-33 in 
Sarcoidosis and a carbon nanotube model of chronic granulomatous disease. Am J Respir Cell Mol Biol. 2016:54:865-71.

60. Wijesekara N, Zhang LH, Kang MH, Abraham T, Bhattacharjee A, Warnock $G L$, Verchere CB, Hayden MR. miR-33a modulates ABCA1 expression, cholesterol accumulation, and insulin secretion in pancreatic islets. Diabetes. 2012;61:653-8

61. Karunakaran D, Richards L, Geoffrion M, Barrette D, Gotfrit RJ, Harper ME, Rayner KJ. Therapeutic inhibition of miR-33 promotes fatty acid oxidation but does not ameliorate metabolic dysfunction in diet-induced obesity. Arterioscler Thromb Vasc Biol. 2015;35:2536-43.

62. Price NL, Rotllan N, Zhang X, Canfrán-Duque A, Nottoli T, Suarez Y, Fernández-Hernando C. Specific disruption of Abca1 targeting largely mimics the effects of miR-33 knockout on macrophage cholesterol efflux and atherosclerotic plaque development. Circ Res. 2019;124:874-80.

63. Gingo MR, Silveira LJ, Miller YE, Friedlander AL, Cosgrove GP, Chan ED, Maier LA, Bowler RP. Tumour necrosis factor gene polymorphisms are associated with COPD. Eur Respir J. 2008;31:1005-12.

64. Leong KG, Karsan A. Signaling pathways mediated by tumor necrosis factor alpha. Histol Histopathol. 2000;15:1303-25.

65. Kusnadi A, Park SH, Yuan R, Pannellini T, Giannopoulou E, Oliver D, Lu T, Park-Min KH, Ivashkiv LB. The Cytokine TNF Promotes Transcription Factor SREBP Activity and Binding to Inflammatory Genes to Activate Macrophages and Limit Tissue Repair. Immunity. 2019;51:241-257.e249.

66. Hayden MS, Ghosh S. Regulation of NF-kB by TNF family cytokines. Semin Immunol. 2014;26:253-66.

67. Dempsey PW, Doyle SE, He JQ, Cheng G. The signaling adaptors and pathways activated by TNF superfamily. Cytokine Growth Factor Rev. 2003;14:193-209.

68. Field FJ, Watt K, Mathur SN. TNF-alpha decreases ABCA1 expression and attenuates $\mathrm{HDL}$ cholesterol efflux in the human intestinal cell line Caco-2. J Lipid Res. 2010;51:1407-15.

69. Liu T, Zhang L, Joo D, Sun S-C. NF-KB signaling in inflammation. Signal transduction and targeted therapy. 2017;2:17023.

70. Marquart TJ, Allen RM, Ory DS, Baldán Á. miR-33 links SREBP-2 induction to repression of sterol transporters. Proc Natl Acad Sci. 2010;107:12228-32.

71. Beutler B. Toll-like receptors: how they work and what they do. Curr Opin Hematol. 2002;9:2-10.

72. Doz E, Noulin N, Boichot E, Guénon I, Fick L, Le Bert M, Lagente V, Ryffel B, Schnyder B, Quesniaux VFJ, Couillin I. Cigarette smoke-induced pulmonary inflammation is TLR4/MyD88 and IL-1R1/MyD88 signaling dependent. J Immunol. 2008;180:1169-78.

73. Geraghty P, Dabo AJ, D'Armiento J. TLR4 protein contributes to cigarette smoke-induced matrix metalloproteinase-1 (MMP-1) expression in chronic obstructive pulmonary disease. J Biol Chem. 2011;286:30211-8.

74. Kawai T, Akira S. Signaling to NF-kB by Toll-like receptors. Trends Mol Med. 2007:13:460-9.

75. Christian F, Smith EL, Carmody RJ. The regulation of NF-KB subunits by phosphorylation. Cells. 2016;5:12.

76. Zhao GJ, Tang SL, LV YC, Ouyang XP, He PP, Yao F, Chen WJ, Lu Q, Tang YY, Zhang $M$, et al. Antagonism of betulinic acid on LPS-mediated inhibition of ABCA1 and cholesterol efflux through inhibiting nuclear factor-kappaB signaling pathway and miR-33 expression. PLoS One. 2013;8:e74782.

77. Campo GM, Avenoso A, D'Ascola A, Prestipino V, Scuruchi M, Nastasi G, Calatroni A, Campo S. Protein kinase a mediated anti-inflammatory effects exerted by adenosine treatment in mouse chondrocytes stimulated with IL13. BioFactors. 2012;38:429-39.

78. Mulay V, Wood P, Rentero C, Enrich C, Grewal T. Signal transduction pathways provide opportunities to enhance $\mathrm{HDL}$ and apoAl-dependent reverse cholesterol transport. Curr Pharm Biotechnol. 2012;13:352-64.

79. Haidar B, Denis M, Krimbou L, Marcil M, Genest J Jr. CAMP induces ABCA1 phosphorylation activity and promotes cholesterol efflux from fibroblasts. $J$ Lipid Res. 2002;43:2087-94.

80. Kritharides L, Christian A, Stoudt G, Morel D, Rothblat GH. Cholesterol metabolism and efflux in human THP-1 macrophages. Arterioscler Thromb Vasc Biol. 1998;18:1589-99.

81. Bortnick AE, Rothblat GH, Stoudt G, Hoppe KL, Royer $\amalg$, McNeish J, Francone OL. The correlation of ATP-binding cassette 1 mRNA levels with cholesterol efflux from various cell lines. J Biol Chem. 2000;275:28634-40.

82. Santamarina-Fojo S, Peterson K, Knapper C, Qiu Y, Freeman L, Cheng JF, Osorio J, Remaley A, Yang XP, Haudenschild C, et al. Complete genomic sequence of the human ABCA1 gene: analysis of the human and mouse ATP-binding cassette A promoter. Proc Natl Acad Sci U S A. 2000;97:7987-92.
83. Qiu Y, Cavelier L, Chiu S, Yang X, Rubin E, Cheng J-F. Human and mouse ABCA1 comparative sequencing and Transgenesis studies revealing novel regulatory sequences. Genomics. 2001;73:66-76.

84. Haidar B, Denis M, Marcil M, Krimbou L, Genest J Jr. Apolipoprotein A-I activates cellular CAMP signaling through the ABCA1 transporter. J Biol Chem. 2004:279:9963-9.

85. Zhao G-J, Yin K, Fu Y-C, Tang C-K. The interaction of ApoA-I and ABCA1 triggers signal transduction pathways to mediate efflux of cellular lipids. Mol Med (Cambridge, Mass). 2012;18:149-58.

86. Geraghty P, Wyman AE, Garcia-Arcos I, Dabo AJ, Gadhvi S, Foronjy R. STAT3 modulates cigarette smoke-induced inflammation and protease expression. Front Physiol. 2013;4:267.

87. Bohadana A, Teculescu D, Martinet Y. Mechanisms of chronic airway obstruction in smokers. Respir Med. 2004;98:139-51.

88. Tang C, Houston BA, Storey C, LeBoeuf RC. Both STAT3 activation and cholesterol efflux contribute to the anti-inflammatory effect of apoA-1/ ABCA1 interaction in macrophages. J Lipid Res. 2016;57:848-57.

89. Beadling C, Guschin D, Witthuhn BA, Ziemiecki A, Ihle JN, Kerr IM, Cantrell DA. Activation of JAK kinases and STAT proteins by interleukin-2 and interferon alpha, but not the T cell antigen receptor, in human T lymphocytes. EMBO J. 1994;13:5605-15.

90. A-Gonzalez N, Hidalgo A. Nuclear receptors and clearance of apoptotic cells: stimulating the Macrophage's appetite. Front Immunol. 2014;5.

91. Wang C, Ding H, Tang X, Li Z, Gan L. Effect of Liuweibuqi capsules in pulmonary alveolar epithelial cells and COPD through JAK/STAT pathway. Cell Physiol Biochem. 2017;43:743-56.

92. Nofer J-R. Signal Transduction by HDL: Agonists, Receptors, and Signaling Cascades. In: von Eckardstein A, Kardassis D, editors. High Density Lipoproteins: From Biological Understanding to Clinical Exploitation. Cham: Springer International Publishing; 2015. p. 229-56

93. Chatterjee $P, A l$-abed $Y$, Sherry B, Metz C. Cholinergic agonists regulate JAK2/STAT3 signaling to suppress endothelial cell activation. Am J Phys Cell Phys. 2009;297:C1294-306.

94. Le Goff W, Zheng P, Brubaker G, Smith JD. Identification of the CAMPresponsive enhancer of the murine $A B C A 1$ gene: requirement for $C R E B 1$ and STAT3/4 elements. Arterioscler Thromb Vasc Biol. 2006;26:527-33.

95. Grabiec AM, Hussell T. The role of airway macrophages in apoptotic cell clearance following acute and chronic lung inflammation. Semin Immunopathol. 2016;38:409-23.

96. Yvan-Charvet L, Pagler TA, Seimon TA, Thorp E, Welch CL, Witztum JL, Tabas I, Tall AR. ABCA1 and ABCG1 protect against oxidative stress-induced macrophage apoptosis during efferocytosis. Circ Res. 2010;106:1861-9.

97. A-Gonzalez N, Bensinger SJ, Hong C, Beceiro S, Bradley MN, Zelcer N, Deniz J, Ramirez C, Díaz M, Gallardo G, et al. Apoptotic cells promote their own clearance and immune tolerance through activation of the nuclear receptor LXR. Immunity. 2009;31:245-58.

98. Morimoto K, Janssen WJ, Fessler MB, McPhillips KA, Borges VM, Bowler RP, Xiao YQ, Kench JA, Henson PM, Vandivier RW. Lovastatin enhances clearance of apoptotic cells (efferocytosis) with implications for chronic obstructive pulmonary disease. J Immunol. 2006;176:7657-65.

99. Kapellos TS, Bassler K, Aschenbrenner AC, Fujii W, Schultze JL. Dysregulated functions of lung macrophage populations in COPD. J Immunol Res. 2018;2018: 2349045.

100. Fond AM, Lee CS, Schulman IG, Kiss RS, Ravichandran KS. Apoptotic cells trigger a membrane-initiated pathway to increase ABCA1. J Clin Invest. 2015;125:2748-58.

101. Nagao K, Kimura Y, Ueda K. Lysine residues of $A B C A 1$ are required for the interaction with apoA-I. Biochim Biophys Acta (BBA). 2012;1821:530-5.

102. Murphy AJ, Woollard KJ, Suhartoyo A, Stirzaker RA, Shaw J, Sviridov D, ChinDusting JP. Neutrophil activation is attenuated by high-density lipoprotein and apolipoprotein A-I in in vitro and in vivo models of inflammation. Arterioscler Thromb Vasc Biol. 2011;31:1333-41.

103. Tabet F, Remaley AT, Segaliny Al, Millet J, Yan L, Nakhla S, Barter PJ, Rye K-A, Lambert $\mathrm{G}$. The $5 \mathrm{~A}$ apolipoprotein A-I mimetic peptide displays antiinflammatory and antioxidant properties in vivo and in vitro. Arterioscler Thromb Vasc Biol. 2010;30:246-52.

104. Sharma S, Umar S, Potus F, lorga A, Wong G, Meriwether D, Breuils-Bonnet S, Mai D, Navab K, Ross D, et al. Apolipoprotein A-I mimetic peptide 4F rescues pulmonary hypertension by inducing microRNA-193-3p. Circulation. 2014;130:776-85.

105. Nashel DJ. Is atherosclerosis a complication of long-term corticosteroid treatment? Am J Med. 1986;80:925-9. 
106. Ayaori M, Sawada S, Yonemura A, Iwamoto N, Ogura M, Tanaka N, Nakaya K, Kusuhara M, Nakamura H, Ohsuzu F. Glucocorticoid receptor regulates ATP-binding cassette transporter-A1 expression and Apolipoprotein-mediated cholesterol efflux from macrophages. Arterioscler Thromb Vasc Biol. 2006;26:163-8.

107. Cazzola M, Page CP, Rogliani P, Matera MG. $\beta 2$-agonist therapy in lung disease. Am J Respir Crit Care Med. 2013;187:690-6.

108. Billington CK, Ojo OO, Penn RB, Ito S. CAMP regulation of airway smooth muscle function. Pulm Pharmacol Ther. 2013;26:112-20.

109. Billington CK, Penn RB. Hall IP: $\beta(2)$ Agonists. Handb Exp Pharmacol. 2017; 237:23-40.

110. Liang B, Wang X, Yan F, Bian YF, Liu M, Bai R, Yang HY, Zhang NN, Yang ZM, Xiao CS. Angiotensin-(1-7) upregulates (ATP-binding cassette transporter A1) ABCA1 expression through cyclic AMP signaling pathway in RAW 264.7 macrophages. Eur Rev Med Pharmacol Sci. 2014;18:985-91.

111. Zhang HT. Cyclic AMP-specific phosphodiesterase-4 as a target for the development of antidepressant drugs. Curr Pharm Des. 2009;15:1688-98

112. Balaguer C, Peralta A, Ríos Á, Iglesias A, Valera JL, Noguera A, Soriano JB, Agustí À, Sala-Llinas E. Effects of simvastatin in chronic obstructive pulmonary disease: results of a pilot, randomized, placebo-controlled clinical trial. Contemp Clin Trials Commun. 2016;2:91-6.

113. Kaczmarek P, Sładek K, Skucha W, Rzeszutko M, Iwaniec T, Dziedzina S, Szczeklik A. The influence of simvastatin on selected inflammatory markers in patients with chronic obstructive pulmonary disease. Pol Arch Med Wewn. 2010;120:11-7.

114. Chen T, Lu L, Xu C, Lin X, Leung Y-k, Ho S-M, Ruan XZ, Lian X. Inhibition role of Atherogenic diet on ethyl Carbamate induced lung tumorigenesis in C57BL/6J mice. Sci Rep. 2017;7:4723.

115. Gong H, He J, Lee JH, Mallick E, Gao X, Li S, Homanics GE, Xie W. Activation of the liver $X$ receptor prevents lipopolysaccharide-induced lung injury. J Biol Chem. 2009;284:30113-21.

116. Varin A, Thomas $C$, Ishibashi M, Ménégaut L, Gautier T, Trousson A, Bergas $V$, JPPd B, Narce M, JMA L, et al. Liver $X$ receptor activation promotes polyunsaturated fatty acid synthesis in macrophages. Arterioscler Thromb Vasc Biol. 2015;35:1357-65.

117. Fessler MB. The challenges and promise of targeting the liver $X$ receptors for treatment of inflammatory disease. Pharmacol Ther. 2018;181:1-12.

118. Chen H, Li Z, Dong L, Wu Y, Shen H, Chen Z. Lipid metabolism in chronic obstructive pulmonary disease. Int J Chronic Obstruct Pulmon Dis. 2019;14: 1009-18.

119. Xuan L, Han F, Gong L, Lv Y, Wan Z, Liu H, Zhang D, Jia Y, Yang S, Ren L, Liu L. Association between chronic obstructive pulmonary disease and serum lipid levels: a meta-analysis. Lipids Health Dis. 2018;17:263.

120. Wang $B$, Tontonoz P. Liver $X$ receptors in lipid signalling and membrane homeostasis. Nat Rev Endocrinol. 2018;14:452-63.

121. Higham A, Lea S, Plumb J, Maschera B, Simpson K, Ray D, Singh D. The role of the liver $\mathrm{X}$ receptor in chronic obstructive pulmonary disease. Respir Res. 2013;14:106

\section{Publisher's Note}

Springer Nature remains neutral with regard to jurisdictional claims in published maps and institutional affiliations.

Ready to submit your research? Choose BMC and benefit from:
- fast, convenient online submission
- thorough peer review by experienced researchers in your field
- rapid publication on acceptance
- support for research data, including large and complex data types
- gold Open Access which fosters wider collaboration and increased citations
- maximum visibility for your research: over 100M website views per year
At BMC, research is always in progress.
Learn more biomedcentral.com/submissions

